\title{
Interaction of social institutions as a vector of personal development
}

\author{
V.E. Kozlov ${ }^{1 *}, A . A$. Timofeev $^{2}$, and G.F. Sadrislamov ${ }^{3}$ \\ ${ }^{1}$ Institute of Pedagogy, Psychology and Social Problems, Kazan, Russia \\ ${ }^{2}$ Institute of Pedagogy, Psychology and Social Problems, Kazan, Russia \\ ${ }^{3}$ Institute of Pedagogy, Psychology and Social Problems, Kazan, Russia
}

\begin{abstract}
The article examines the potential of the social institutions' interaction in the context of the personal development and socialization ideas. Considering the traditional Russian mentality and the characteristics of the Russian education system, the authors focus on the new conditions of socialization, revealing the methodology for the effective social practices' development.
\end{abstract}

\section{A problem statement}

Questions about personal socialization, the individual's entry into society, determining the social role and significance of each person for the world and the professional activity for science, culture and economics integrate a significant layer of research in the social sciences and humanities. Society consists of individuals, whose life activity, although absolutely diverse, nevertheless obeys tasks and is reflected in the functions of the social world order [1, 2], [3]. Socialization of the individual presupposes the assimilation of behavior and activity culture within the framework of the individual's community (family, group, professional and civil society).

This process is two-sided - society "dictates", and the individual "reproduces" certain rules of life, thereby being included in the functioning of society in its socio-economic context. It cannot be denied the emerging socio-economic needs of society in the upbringing of a growing person.

Ideological pressure, even if it is not explicitly present in the social system, exists, giving rise to norms, rights and rules for the existence of civil society, based on "eternal" values, cultural and mental traditions, religious dogmas, family truths and personal ideas about culture and behavior, social activity.

Thus, modern society has global differences in the methods and types of socialization at the national level, while there is also a significant layer regarding the general problems of socialization of youth: the problematic nature of growing up (according to T. Parsons "structured irresponsibility" [4]), informality, protest activity, the need for family and psychological and pedagogical support.

\footnotetext{
${ }^{*}$ Corresponding author: ipcs-profped@yandex.ru
} 
In the current conditions of multifactorial life, rapid transformations, globalization and digitalization, information openness and accessibility lead to a serious blurring of the boundaries of socialization, a change in the roles of social institutions, traditional social and educational practices.

Now more than ever, there is a gap in the continuity of generations due to the speed of information exchange and the change in technology [5]. However, it is important to defend the interests of the young generation living in a qualitatively new world and still willing to participate in active social activities, building their own conditions for growing up and living, using the potential of traditions, historical and genetic memory, cultural and religious identity [6]. This is what led us to the need to consider the interaction of social institutions as a potential for the development of a full-fledged member of society and active socialization.

\subsection{The objective of the work}

By first proposing the term "social institution", G. Spencer identified the following types of them: industrial, professional, political, ritual, church, home [7].

In the contemporary period, at the level of actually obtained results of functioning, researchers distinguish the following types of global social institutions: family, state, business, education and religion and their derivatives [8-10] each of which is designed to satisfy a number of needs.

The term "social institution" is rather vague, its ideas have changed in relation to commitment from the necessary stability of social institutions to its dynamism in conditions of high turbulence of the world order and conformity to the social order [11-14].

The stable system of fundamental human values' development will contribute to the spectrum of phenomena of different levels from personal to state - from creating a stable career and successful in a personal and professional sense of life to strengthening statehood from social, economic, and environmental positions [15].

So, meaning by "social institution" an artificially created form of organization of people's life, which determines the formation of its norms and culture, we believe that none of the typologies can be complete and homogeneous, every day new social practices appear, the success of which is confirmed by the real results of socialization youth at different levels.

That is why we will try to highlight the most general productive concepts of organizing the interaction of social institutions from the standpoint of the young person's personality development.

\section{Materials and the results of the research}

1) Methodological concept. The neoinstitutional approach forms a global vision of the real functioning of social institutions. Its essence lies in the representation of institutions as "rules of the game" for a person and society (D. North [16]) formal and informal rules governing the practice of life, that is, institutions are a product of social interaction of society actors (K.V. Pavlenko [17]).

The emphasis in such a strategy is seen in the focus on "customer satisfaction" on the one hand - there are many possible acceptable behavioral alternatives, and the constraining factor in the form of conditional rationing - on the other. This emphasis strengthens the subject-subject approach, which determines the recognition of the activity of the social action subject and the need to form the social responsibility for the implementation of the content and forms of life in society. A person should not just adapt to society, 
fundamentally breaking the own ideas, but act from the standpoint of self-actualization, "Self- concept", self-realization of the personality of creative abilities [18].

Of course, such a position requires not anarchic freedom of social institutions actions that allow any development of events (up to destructive ones), but the provision of possible alternatives to personal self-realization in normalized freedoms. Then the transition from the object position of the influence of society to the subjective position of its full member will become possible. Here social institutions act as keepers of traditions, developing with each new generation and its values, intelligently innovating and transforming their organizational forms and norms.

2) Theoretical concept. In view of the unsettled system of "social institution" concepts and the variety of researchers' positions, we can offer our own definition that connects the personality of a young person in the future of its development, the accumulated baggage of personality socialization systems in various world order, the traditional education system (as a system of development, upbringing and training).

By a social institution, we mean a set of continuously operating legitimate organizational forms that translate social experience through ordered social practices that are important for the transmission of norms, meanings and values of the functioning of the state, society and person.

Successful self-realization of any person requires social acceptance by others of the results of his social activity. The modern social situation dictates the need to develop an active life position that stimulates people to use all their potential abilities for selfrealization, professional and personal growth within the framework of those social conditions and the culture in which they grow and develop.

In the context of educational activities, it is especially important to "reach out" to young people, to "cross" the line of negative attitudes towards "educators", to "impose" ideals. Taking into account the inevitably existing conflict of "fathers and children", which is further exacerbated by the new trends in digitalization, this is not easy to do. Of fundamental importance is the emphasis on the social inclusion of all subjects of education and the provision of pedagogical interaction of all social institutions in this process. Each of the social institutions is designed to satisfy a number of needs in the upbringing of young people, conditioning the possibilities of influencing people's behavior through established rules, system values and social projection.

3) Organizational concept. The functioning of social institutions has a bi-directional relationship - a person (a group of people) influences society to the same extent that society influences this person, creating a constructive and destructive effect. That is why the formation of the social institutions interaction sphere, their common vector requires special attention when focusing on the younger generation.

Mild conditions should be created with the formation of stable ties between the subjects; a formalized organization with specific social roles has been implemented; a regulatory framework has been determined that ensures the regulation of a social institution; the legitimacy of the activity and the planned performance are ensured.

Here, a fundamental role is played by the interaction of social institutions, which presupposes a system of connections between various organizational forms of social institutions with a certain coordination of actions to solve common problems. Actions include: joint planning and programming; creation of a common resource base; formation of a range of actions (activities); joint reflection of the results, etc.

Accordingly, for the organizational interaction of social institutions, the following should be available: a) a trained staff of a social institution representatives; b) the functions of each participant in the interaction of social institutions are determined; c) the criteria for the effectiveness of the social institutions' interaction for solving the assigned tasks are determined. 
4) Technological concept. The interaction of social institutions is functionally expressed in the formation of a system for involving young people into real social practices through single social actions. Turning into a "routine" (becoming habitual), social actions through repeated repetitions can themselves become social institutions actively supported by society, as, for example, happened with the practice of volunteering. The presence of social practices characterizes the inclusion of society and its informal support, conditioned by norms, stability and technological effectiveness. However, from the standpoint of the influence on a young person and the formation of the social subjectivity, the parameters of the choice of social actions and the acceptance of all norms [19, 20]. Social subjectivity means an active personal position and participation in social actions, as well as acceptance by society as a subject, and not an object of action - a partner of interaction. Only in this case paternalism can be replaced by real (and not imposed) value orientations and meanings experienced and accepted by the young person.

5) Pedagogical concept. Since we are talking about the development of a young person, the family and the educational system will play a decisive role in the interaction of social institutions, determining precisely the pedagogical interaction of social institutions. In view of the fact that the educational system is the most widespread for young people, we see it as the most important pedagogical format of interaction between social institutions. We understand it as a specially organized multifactorial process that affects the education, upbringing and development of subjects of education [21].

In modern conditions, the essence of pedagogical interaction, both within the educational process and outside it, has changed significantly [22, 23]. The transformation of traditional pedagogical practices took place taking into account external conditions and a change in the paradigm of education. On the one hand, the emphasis on the educational functions of the teacher is reduced, on the other hand, new opportunities for joint actions of the pedagogical community, educational organizations and other social institutions appear in the formation of an educational field that can provide society's needs for the qualities of a person of the future development.

The range of components of pedagogical interaction is very extensive [24]: integration, cooperation, communication, coordination, coordination, etc. Each of these components implies the presence of the following characteristics of the pedagogical interaction subjects: mutual knowledge, mutual conditioning, mutual influence, joint activities, exchange of resources, communication and achievement of joint effectiveness. The following main aspects of the pedagogical interaction of social institutions in the development of a young person are fundamental:

1) not only representatives of the pedagogical community, but also representatives of other social institutions prepared for pedagogical influence, as well as the students themselves (collectives of students, communities) can act as active subjects of pedagogical interaction of social institutions (that is, transmitting pedagogical activity in social practices);

2) pedagogical interaction of social institutions can be direct and mediated, arise planned or spontaneously. Accordingly, the readiness of social institutions representatives for pedagogical interaction within the framework of social practices is a prerequisite. It is very easy to lose the confidence of a young person, to disappoint him/her, therefore it is important to carry out psychological and pedagogical support of all social practices and pedagogical reflection, consistently "moving" in the direction of socialization, realizing the irreversibility of one's actions;

3) the regulation of the pedagogical interaction of social institutions should not be formal, should provide for a variety of forms and events in which the young generation can be involved (in accordance with age capabilities, personal characteristics and inclinations). When a socially significant goal does not become personally significant, does not actualize 
any human need, it acts as an unwanted need. It is important to make this aspect attractive to young people, then the involvement, activity of actions and the dissemination of social practices that have high social significance and pedagogical effect are guaranteed.

Thus, the basic educational interactions "personality - family", "personality educational environment", "personality - society" (including social networks, are significantly expanded through the possibility of all social institutions' interaction).

6) Reflective concept. Replication and search for effective social practices in order to develop the personality as an active member of society involves the identification and analysis of criteria for the interaction of social institutions. We believe that these include the following: breadth (as the number of social institutions included in the process, expanding the range of opportunities); intensity (as the frequency of opportunities for personal realization formation); activity (as the degree of participation in social activities); positivity (as creating an optimal environmental climate); effectiveness (as the presence of personality-oriented results in the current and future period).

\section{Conclusions}

So, the concepts highlighted by the authors expand the methodology of organizing the interaction of social institutions, forming the main positions and acting in the interests of the social world order development. The interaction of social institutions is designed to create a new productive dynamic system that has a target orientation and forms strategic life attitudes and value orientations. Its uniqueness of interaction lies in an attempt to avoid the formalism and rigid norms of joint activity in the development of the individual outside the family and education, providing real opportunities for the development and socialization of the person of the future with an emphasis on the moral guidelines and common values.

\section{References}

1. E.Yu. Pochtareva, Bulletin of Perm University. Philosophy. Psychology. Sociology, 4, 563-575 (2017)

2. A.P. Fomina, Problems of modern education, 6, 142-149 (2018)

3. O.F. Baryakhtar, Bulletin of Kemerovo state University, 2 (74), 85-91 (2018)

4. T. Parsons, On the structure of social action p.880 (Moscow: Academic Project, 2000)

5. G. Bechmann, Modern society: risk society, information society, knowledge society p.248 (Moscow: Publishing house «Logos», 2010)

6. D.A. Leontiev, A.A. Lebedeva, V.Yu. Kostenko, Education issues, 2, 98-112 (2017)

7. G. Spencer, Sociology as a subject of study: texts on the history of sociology of the XIX-XX centuries p.381 (Moscow: Academic Project, 1994)

8. M.M. Yusufov, Historical and socio-educational thought, 4, 162-166 (2011)

9. S.S. Frolov, Sociology of power, 3, 25-35 (2010)

10. K.Yu. Mikhaleva, N.L. Polyakova, Moscow University Bulletin. Series 18. Sociology and Political Science, 2, 117-132 (2012)

11. O.P. Mezhevnikova, T.V. Ukhina, Service plus, 14 (1), $41-48$ (2020)

12. G.I. Gerasimova, Theory and practice of social development, 3, 61-63 (2014)

13. N.N. Ravochkin, N.S. Bondarev, G.S. Bondareva, Sociodynamics, 4, 85-98 (2020)

14. A.A. Chaplygin, E.A. Ageeva, Bulletin of the expert Council, 3 (14), 103-107 (2018) 
15. E.M. Dorozhkin, E.Yu. Shcherbina, Bulletin of Tomsk state University, 381, 184-188 (2014)

16. D. North, Institutions, Institutional Change and Economic Performance p.180 (Moscow: Foundation for Economic Books "Beginnings", 1997).

17. K.V. Pavlenko, Journal of Sociology and Social Anthropology, 13 (1), 90-100 (2010)

18. A.K. Savina, Values and meanings, 2, 114-130 (2017)

A. A. Dargan, Knowledge. Understanding. Skill, 2, 82-94 (2019)

19. A.A. Merzlyakov, Sociological Science and Social Practice, 4, 95-104 (2018)

20. E.Y. Levina, A.A. Timofeev, Kazan Pedagogical Journal, 6, 108-112 (2019)

21. G.M. Gadzhiev, E.E. Kvimsadze, Bulletin of the Dagestan State Pedagogical University. Psychological and pedagogical sciences, 2 (19), 23-27 (2012)

22. A.I. Protsenko, Bulletin of Orenburg State University, 5 (217), 66-72 (2018)

23. T.Yu. Skamyanova, Higher education today, 9, 86-90 (2015) 